\title{
Electronic Cash In E-Commerce: Comparative Analysis Of Views Of Hispanic And African-American Business Owners
}

\author{
James L. Morrison, (Email: jlm@udel.edu), University of Delaware \\ G. Titi Oladunjoye, (Email: titi@asurams.edu), Albany State University \\ Young S. Kwak, (Email: ykwak@dsc.edu), Delaware State University \\ Michael Czarkowski, (Email: mczar@wilmcoll.edu), Wilmington College
}

\begin{abstract}
Based on a survey of 1000 Hispanic and 1000 African-American business owners on the impacts e-commerce and e-cash are expected to have upon business practices, there were significant discrepancies between perceptions of these two groups regarding their ability to track and retain customers and to authenticate the source of e-cash payments. In addition, while both groups of owners agreed that e-cash will likely replace traditional currency used in commercial transactions between consumers and business, they both are uncertain as to what degree central banks of countries should regulate and how much freedom the private sector should have for developing new forms of e-cash. Hispanic business owners generally are more receptive to e-commerce viewing it as not making marketing strategies more difficult while African-American owners generally perceive enhanced issues to be resolved.
\end{abstract}

\section{Introduction}

$B$ oth the small business owner and the large corporate enterprise are in the midst of adapting Internet technology to supplement traditional forms of retailing goods and services to customers. Gary Schneider (2002) of the University of San Diego in his text, New Perspectives on E-Commerce, references Internet technology to electronic commerce. He defines electronic commerce (e-commerce) as conducting the selling, buying, logistics, and other organizational activities of a company via the Web. The total value of e-commerce business is growing rapidly in regard to the overall size of the U.S. economy. Although consumer shopping on the Web is expected to exceed $\$ 300$ billion by 2003 , Schneider (2002) alludes to the fact that electronic commerce is much broader and encompasses many more business activities than just Web shopping.

An integral part of Internet commerce is the use of electronic cash (e-cash) as the medium of exchange. The cost savings in reducing the time and paperwork involved in completing a transaction with a customer is one of the primary attributes associate with the adoption of electronic payment systems. E-cash is often referred to as digital cash, digital coins, digitized coins, electronic money, and electronic checks. These forms of electronic money can be transmitted by wire from one computer to another by consumers and businesses outside of the public international banking system (Schneider, 2002).

The total value of business-to-consumer e-commerce is growing rapidly in regard to the overall size of the U.S. economy. According to Jupiter Media Metrix, Inc., online sales are expected to top $\$ 39$ billion this year (2002), up from $\$ 30$ billion in 2001. Anthony Noto, Internet analyst at Goldman, Sacks \& Co. thinks online

Readers with comments or questions are encouraged to contact the authors via email. 
consumer sales will increase from 1.8 percent of total sales in 2001 to 5 percent by 2006 (Green, 2002). Online customer orders grew from approximately 68 million in first quarter of 2001 to 91 million in first quarter of 2002. The average spent on an online purchase was $\$ 127$ per purchase in 2001 , up 5.3 percent from $\$ 120$ a year earlier. It is very evident that online sales are becoming increasingly popular as consumers become more familiar with ecommerce. Similarly, businesses are realizing the benefits of e-commerce as they attempt to lower production costs, improve customer service, and increase productivity (Green, 2002).

\section{E-Commerce And The Minority-Owned Business Enterprise}

E-commerce is an alternative to traditional 'brick and mortar' marketing strategies to gain market share. Internet technology is often considered the 'driving force' behind the expansion of e-commerce as a company strategy. Of particular interest here is the impact e-commerce is having and likely to have upon minority-owned business enterprises in the United States. Specifically, the research focus here is upon determining how Hispanic and African-American business owners perceive e-commerce and e-cash payment systems impacting upon current company operations.

\subsection{Growth Rates Of Minority-Owned Business Enterprises}

According to a recent U.S. Census Report, there are 20,821,934 businesses operating within the boundaries of the United States. Of this number, 3,034,033 are minority owners. Minority is referenced as African-American, Hispanic/Latino, Asian and Pacific Islander, and American Indian/Alaskan Native owners, representing approximately 14 percent of all U.S. firms. Of particular interest in this study are the 823,499 African-American entrepreneurs and 1,199,876 Hispanic. There has been a growth rate of 30 percent in the number of minority business between 1992 and 1997, which is approximately 7 percent faster growth than non-minority businesses. In addition, 60 percent per Hispanic and 55 percent of African-American business enterprises have gross receipts of over $\$ 10,000$. With this significant growth in minority entrepreneurs, their perceptions of e-commerce as an integral part of their future marketing strategies are of considerable interest to policymakers (Langston, 1997).

\subsection{Awareness Of E-Commerce Impacts By Minority-Owned Businesses}

In terms of e-commerce awareness, based on a study of minority-owned businesses by the U.S. Department of Commerce, 60 percent understood the benefits of e-commerce (eg., bigger markets, higher profits, lower costs, remaining competitive, etc.). In addition, it was reported that approximately 90 percent of minority-owned businesses relied on some form of information technology to do their work. Correspondingly, the survey estimated that between 79 percent and 91 percent of minority businesses were connected to the Internet. These figures are comparable to 1999 Dun \& Bradstreet research indicating that 93 percent of firms with 26-100 employees had Internet connectivity. Moreover, between 42 and 56 percent of minority business had websites. Research on overall small and medium size business indicates that 53 percent of small business and 47 percent of medium size business had web capability (Dun \& Bradstreet, 1999). Finally, most minority firms involved in e-commerce participate in business-to-consumer (B2C) transactions rather than business-to-business (B2B) sales. In this regard, approximately 50 percent of Hispanic and 47 percent of African-American businesses were engaged in the business-to-consumer sales (Lopez-Aqueres, 2001).

\subsection{Regulating E-Cash and E-Commerce}

With the emergence of new forms of electronic cash associated with e-commerce transactions, price and financial stability are becoming more of a concern to all those competing for customer dollars. In a similar regard, market expectations become a barometer of future success and failure, especially for those entrepreneurs seeking to advance both short-term and long-term company profits. What our economy is about is building consumer and business confidence. Perceptions as to what is occurring in the economy result in expectations that impact upon decision makers in terms of building inventory and eventual sales. Any sudden jolt to economic stability, whether through terrorism, sudden price movements in energy, or innovative e-commerce cash systems, impacts upon the ability to compete especially a global marketplace. 
As issues arise in e-commerce, will government leave the cyber market and its evolving electronic payments system alone, or will it intervene? For example, R. Alton Gilbert, an economist with the Federal Reserve Bank of St. Louis, contends that the answer hinges on how regulators view the safety and soundness of emerging electronic payments systems (Dorn, 1997). David Chaum, founder of DigiCash, suggests that e-cash can come very close to having the attributes of paper currency (particularly anonymity) without the costs associated with processing it. Alan Greenspan argues that we must be careful not to impose rules that inhibit its development (Dorn, 1997). He goes on and states that consumers and entrepreneurs will determine what forms of e-cash will be accepted, not government. George Selgin, an economist at the University of Georgia, argues that central banking systems such as the U.S. Federal Reserve system will need more discretion in how to monitor the movement of digital cash (e-cash) within the boarders of the United States (Elstrom, 2001).

\section{Hypothesis}

Since there has been a systematic growth in businesses owned by Hispanics and African-Americans over the past decade, and since these businesses would likely have a website or would be considering one to complement existing 'brick and mortar' operation, investigating their perceptions of electronic money, considered by many as a vital component to Internet commerce, would give us insight as to the seriousness of e-commerce (specifically the Internet) as a marketing strategy. Therefore, the hypothesis for the study is that there are no significant discrepancies among the perceptions of Hispanic and African-American business owners as to the impact e-commerce and ecash is expected to have upon the marketing and selling of products and services.

Because of similar race, ethnicity, culture or language, minority-owned businesses may have a competitive edge in serving emerging markets in the United States and abroad. If so, minority business enterprises should exploit their competitive advantages by using the Internet more aggressively to produce product exposure and increase business in these areas. Since minority-owned businesses generally use computers as part of everyday operations and also have access to the Internet via websites, their perspective as to the direction e-commerce is taking will tell us how aggressive they are likely to be in the future in marketing their products and services. In terms of the availability of e-cash, what confidence do they have in this new form of currency exchange? In other words, is there an insecurity on the part of minority own businesses as to use of e-cash? Is e-commerce perceived as something positive, neutral or wait and see attitude? Do minority own businesses see a potential return for investment in Internet technology, given their customer base? Information is sought to resolve some of these questions in an effort to determine if they perceive increased market opportunities justifying further investment in Web technology.

\section{Methodology}

A survey instrument was sent out to 1000 Hispanic and a 1000 African-American owned business enterprises randomly selected from the National Directory of Minority-Owned Business Firms (2001). An analysis of variance statistical measure was utilized to test the significance in the discrepancies of the perceptions of the respondents. The survey instrument consisted of two segments; one identifying possible concerns related to retaining, tracking, and predicting customer needs for maintaining and/or expanding market share; and secondly, delineating the impacts electronic money is likely to have upon price and financial stability as everyday business practices are carried out.

\section{Findings}

Surveys were received from a total of 376 individuals. Of these, 9 were eliminated from the sample due to illegible responses or other reasons. For the study, responses used were 175 Hispanic and 192 African-American business owners. Therefore, the total sample for the study was 367 responses which includes a 17.5 percent response rate for Hispanic owners and 19.2 percent for African-American owners.

\subsection{E-Commerce Impacts Upon Customer Relations}


There were significance discrepancies in the perceptions of Hispanic and African-American owned business enterprises in regards to e-commerce competition impacting upon the ability to retain, track and predict customer needs. While Hispanic business owners $(\mathrm{M}=3.01)$ were neutral on e-commerce impacts upon the ability to retain customers, African-American business owners ( $\mathrm{M}=3.34)$ perceive it would be more difficult to do so (Table 1). When asked about ecommerce impacts upon their ability to track their customers, the opposite was evident. In this instance, while the African-American business owners $(M=3.09)$ were neutral on this perception, Hispanic owners $(\mathrm{M}=2.76)$ disagreed that ecommerce would affect their ability to do so. Finally, both groups of respondents to the survey disagreed with the view that predicting customer needs would be more difficult if e-commerce was more commonplace ( $\mathrm{M}=2.65$ and $\mathrm{M}=2.85$ respectively) (Table 1$)$.

Table 1 - E-Commerce Impacts Upon Customer Relations As Viewed By Hispanic And African-American Owned Business Enterprises

\begin{tabular}{lcccc}
\hline Item & \multicolumn{3}{c}{ (Mean Scores) } \\
& $\begin{array}{c}\text { Hispanic } \\
\mathrm{N}=175\end{array}$ & $\begin{array}{c}\text { African-Am. } \\
\mathrm{N}=192\end{array}$ & T Value & Probability \\
\hline Retaining Customers & 3.01 & 3.34 & -3.44 & $.0006^{*}$ \\
Tracking Customers & 2.76 & 3.09 & -3.36 & $.0008^{*}$ \\
Predicting Consumer Needs & 2.65 & 2.85 & -2.13 & $.0337^{*}$ \\
Predicting E-cash Sales & 3.29 & 3.26 & 0.45 & .6515 \\
Holding Market Share & 3.05 & 3.02 & 0.48 & .6325 \\
\hline
\end{tabular}

Note: Significant at 05 level of confidence

Rating Scale - $1=$ Strongly disagree; $3=$ Neutral; $5=$ Strongly Agree

Hispanic $(M=3.29)$ and African-American $(M=3.26)$ business owners both agreed in the rate ecommerce sales are expected to increase but were both neutral on being able to hold market share as a result of e-commerce competition ( $\mathrm{M}=3.05$ and $\mathrm{M}=3.02$ respectively) (Table 1$)$.

\subsection{E-Cash Perceptions}

Both Hispanic (M=3.61) and African-American business owners $(M=3.67)$ similarly agree that the privacy issues remain related to securing e-cash as totally safe in its transmission by wire. However, there was agreement in perceptions of the two respondents regarding private sector leadership in developing e-cash alternative payment systems and authenticating ownership of e-cash used during the purchasing process (Table 2). Hispanic business $(\mathrm{M}=2.88)$ owners disagreed that establishing authentication of e-cash sources is impossible while African-American owners $(\mathrm{M}=3.07)$ are more neutral on the issue. On the other hand, African-American and Hispanic owners agreed that the private sector will lead in developing safe and secured new forms of e-cash as ecommerce technology advances (Table 2).

\subsection{Regulating E-Cash Development}

There seems to be some uncertainty as to the how new forms of e-cash should be regulated and how much freedom the private sector should have in developing new kinds of electronic payment systems. Both groups of respondents are relatively unsure about the need to regulate e-cash by means of a worldwide public banking system. Hispanic ( $M=3.01)$ and African-American $(M=3.05)$ owners were neutral on the perception of whether banks need to restrain from regulating new forms of e-cash as they emerge (Table 3). However, both groups indicated that there probably will be less of a role for central banks among countries around the world to monitor e-cash usage as part of e-commerce. On the other hand, Hispanic $(\mathrm{m}=3.45)$ and African-American $(\mathrm{M}=3.55)$ owners both agreed that e-cash will introduce more uncertainty in the purchasing process but similarly disagreed with the perception that the private sector should be given a free hand to develop new forms of e-cash as part of e-commerce transactions $(\mathrm{M}=2.86$ and 
$\mathrm{M}=2.91$ respectively) (Table 3$)$.

Table 2 - E-Cash Impacts Upon E-Commerce

As Perceived By Hispanic And African-American Owned Business Enterprises

\begin{tabular}{lcccl}
\hline Item & \multicolumn{2}{c}{ (Mean Scores) } & & Probability \\
& Hispanic & African-Am. \\
$\mathrm{N}=175$ & $\mathrm{~N}=192$ & $\mathrm{~T}$ Value & & \\
\hline Protecting Cons. Privacy & 3.61 & 3.67 & -0.83 & .4052 \\
E-Cash Replaces Checks & 3.68 & 3.63 & 0.41 & .6832 \\
Intro. Of Uncertainty & 2.71 & 2.83 & -1.42 & .1557 \\
Authentication of E-Cash & 2.88 & 3.07 & -2.05 & $.0405^{*}$ \\
Private Sector Leadership & 3.38 & 3.59 & -1.68 & .0750 \\
\end{tabular}

Note: Significant at .05 level of confidence

Rating Scale - 1 = Strongly disagree ; $3=$ neutral; 5 = Strongly Agree

Table 3 - Regulating E-Commerce Currency

As Viewed By Hispanic And African-American Owned Business Enterprises

\begin{tabular}{|c|c|c|c|c|}
\hline \multirow[t]{2}{*}{ Item } & \multicolumn{2}{|c|}{ (Mean Scores) } & \multirow[b]{2}{*}{ T Value } & \multirow[b]{2}{*}{ Probability } \\
\hline & $\begin{array}{r}\text { Hispanic } \\
\mathrm{N}=175\end{array}$ & $\begin{array}{l}\text { African-Am. } \\
\quad \mathrm{N}=192\end{array}$ & & \\
\hline Restrained Reg. & 3.01 & 3.05 & -.52 & .6055 \\
\hline Priv. Sect. Free to Exp. & 2.86 & 2.91 & -.41 & .6845 \\
\hline Dominant Role/Banks & 3.19 & 3.32 & -1.39 & .1641 \\
\hline Tracking Major Prob. & 3.02 & 3.09 & 1.13 & .2579 \\
\hline Volatility to Trade & 3.10 & 3.16 & -.60 & .5487 \\
\hline Reducing Uncertainty & 3.45 & 3.55 & -.98 & .3267 \\
\hline
\end{tabular}

*Significance at .05 level

Rating Scale - 1 = Strongly disagree ; 3=neutral; 5 = Strongly Agree

\section{Conclusions}

Based upon the data gathered from the survey, it may be concluded that both Hispanic and AfricanAmerican business owners are hesitant in their perceptions of e-cash and its impact upon ecommerce marketing strategies. While there are significant discrepancies regarding the ability for them to track and retain customers as ecommerce expands and to authenticate the source of e-cash payments, there is general agreement on other aspects of e-commerce. While both groups agreed that e-cash will likely replace traditional currency/coins and checks, they both are uncertain as to what degree central banks of countries should regulate and how much freedom should the private sector be given to develop new forms of e-cash. Therefore, it may be concluded that although Hispanic and African-American business owners perceive new forms of e-cash and the expansion of ecommerce as inevitable trends, there is also perceived a considerable degree of uncertainty as to how everything will play out.

Therefore, the hypothesis that there are no significant discrepancies among the perceptions of Hispanic and African-American business owners was rejected. With a growth rate among minority business owners expected to increase as the U.S. population continues to become more diverse, e-commerce is expected to become more integral part of business operations. In this regard, it may be appropriate to initiate additional training programs for minority owners especially in regards to the use of electronic payment systems (e-cash), its benefits, and its impact upon enhancing business operations. It may be concluded that minority owners are very much aware of the general aspects 
of e-commerce, but there is great uncertainty as to how electronic payments systems can be secure and how consumer privacy can be protected using present Internet technology.

\section{References}

1. Dorn, James (Ed.) (1997). The future of money in the information age. Washington, DC: Cato Institute, $171 \mathrm{pp}$.

2. Dun \& Bradstreet (2000). $19^{\text {th }}$ annual small business survey. Murray Hill, New Jersey: Office of Strategic Planning and Research.

3. Elstrom, Peter (2001, January 22). "Dead companies walking.” Business Week, p. 63

4. Green, Heather (2002, April 22). "Lessons of the cyber survivors: E-tailers have learned from their past blunders." Business Week, p. 42.

5. Lopez-Aqueres, Waldo (2001). Minority businesses' use of internet technology. Washington, DC: U.S. Department of Commerce, $44 \mathrm{pp}$.

6. Langster, Ronald (2001). State of minority business: 1997 survey of minority-owned business enterprises: An initial analysis plus policy \& research implications. Washington, DC: US Department of Commerce, $25 \mathrm{pp}$.

7. Mandel, Michael (2001, December 17). “Money, money, everywhere: High liquidity won’t spur inflation." Business Week, p. 26.

8. National Directory of Minority-Owned Business Firms, $11^{\text {th }}$ Edition (2001). Washington, DC: Business Research Services, Inc.

9. $\quad$ Popper, Margaret (2002, March 4). “Inflation's gone: That's a good thing, right?” Business Week, p. 60.

10. Santomero, Anthony (2002). "What monetary policy can and cannot do." Harvard Business Review, Q1, pg. 1.

11. Schneider, Gary P. (2001). New perspectives on e-commerce. Boston, MA: Thomson: Learning, pp. 156 pp.

12. Tomas Rivera Policy Institute. (2001, February 22) "MBE participation in electronic commerce in the emerging minority marketplace: The new realities for minority business in the digital economy 2000." Washington Post, p. 15 (reported).

13. Web Server Statistics Page. (2002) http://cyberatlas.Internet.com 